\title{
Staphylococcus aureus resistente a meticilina asociado a la comunidad (SARM-AC): comunicación de los primeros cuatro casos pediátricos descritos en Hospital de Niños Roberto del Río
}

\author{
Mirta Acuña, Dona Benadof, Carla Jadue, Juan C. Hormazábal, Pedro Alarcón, Julio Contreras, \\ Ramón Torres, Cristóbal Mülchi, Carolina Aguayo, Jorge Fernández y Pamela Araya
}

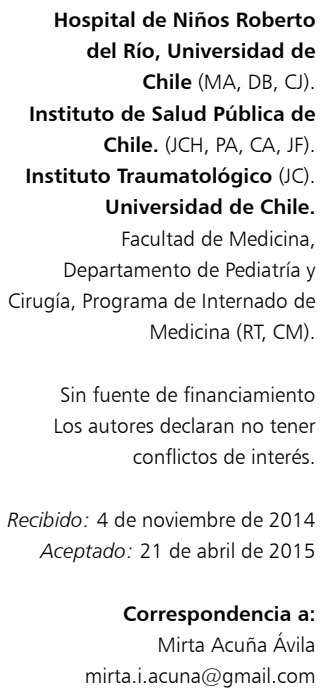

Sin fuente de financiamiento Los autores declaran no tener conflictos de interés.

Recibido: 4 de noviembre de 2014 Aceptado: 21 de abril de 2015

Correspondencia a: Mirta Acuña Ávila mirta.i.acuna@gmail.com

Community associated-methicillin-resistant Staphylococcus aureus (SAMR-AC): comunication of the first four pediatric cases in the Roberto del Rio Children's Hospital

Staphylococcus aureus is a known pathogen in pediatric patients that produces skin infections, cutaneous abscess, cellulitis and osteoarticular infections. Most of these infections are produced by a meticilin susceptible strain. The community associated methicillin resistant Staphylococcus aureus was published for the first time in 1993, ever since then is has been recognized as a cosmopolite pathogen. The first report in Latin America was published in 2003, and in Chile in 2008 from adult patients that have reported traveling to other countries. The following series describes four pediatric cases, all school-aged children, diagnosed since 2012 with clinical followups and molecular studies. Two cases presented as osteomyelitis of the lower extremity; and one presented as arm cellulitis. These three cases had Panton Valentine leukocidine (PV-L) negative strains from the clone complex 8. The last case presented a renal abscess, the strain was PV-L positive from the clone complex 30 . This case series constitutes the first pediatric case report in Chile.

Key words: Methicillin resistant Staphylococcus aureus, community associated, pediatric cases, multilocus sequence typing.

Palabras clave: Staphylococcus aureus resistente a meticilina, comunidad, casos pediátricos, secuenciamiento multilocus.

\section{Introducción}

S taphylococcus aureus es uno de los agentes más frecuentemente asociados a infecciones nosocomiales y de la comunidad, ocupando un lugar protagónico dentro de las causas de infecciones de piel y tejidos blandos, bacteriemias, osteomielitis y endocarditis, tanto en adultos como en niños ${ }^{1}$. En los años cuarenta, con el descubrimiento de la penicilina, se abrieron las puertas al tratamiento de infecciones originadas por este patógeno, pero rápidamente emergieron cepas resistentes a través del mecanismo de producción de enzimas $\beta$ lactamasas ${ }^{2,3}$. En 1960 como nueva alternativa terapéutica se sintetizó la meticilina, antimicrobiano betalactámico resistente a estas $\beta$ lactamasas; sin embargo, con el tiempo también aparecieron cepas resistentes a esta molécula con una CIM $>4 \mu \mathrm{g} / \mathrm{ml}^{4-6}$, identificadas como Staphylococcus aureus resistente a meticilina (SARM). Estas cepas se caracterizan por estar principalmente ligadas al ambiente hospitalario y por poseer en su pared celular una proteína fijadora de penicilina con menor afinidad por los $\beta$ lactámicos. Desde entonces, las tasas de infecciones causadas por este agente fueron en aumento, transformándose en un problema de infecciones asociadas a la atención de salud (IAAS) ${ }^{7}$.
A comienzos de los años 90, en Australia se describió una nueva cepa de SARM, no relacionada a infecciones intrahospitalarias, que se denominó SARM adquirido en la comunidad (SARM-AC) ${ }^{8-10}$. En esta cepa se describió la presencia del gen leucocidina Panton Valentine (PV-L), por lo que se utilizó como gen marcador de SARM-AC. El gen PV-L sintetiza una toxina que actúa sobre los leucocitos produciendo necrosis tisular, siendo un importante factor de virulencia de esta bacteria ${ }^{11-13}$. Sin embargo, no todos los SARM-AC portan este gen, y cada vez con mayor frecuencia se han descrito cepas de SARM-AC PV-L negativas ${ }^{14,15}$.

En Latinoamérica, los primeros reportes de casos de infecciones por SARM-AC tuvieron lugar en Uruguay en el año $2001^{16}$. A partir de 2006 se comunicaron los primeros casos en Chile, correspondiendo a pacientes adultos ${ }^{17}$. Debido a estos hallazgos, a partir de 2007 el Instituto de Salud Pública (ISP), Laboratorio de Referencia de nuestro país, comenzó a realizar una vigilancia de laboratorio de este agente, incluyendo la confirmación microbiológica y caracterización molecular ${ }^{15,18}$. Presentamos los primeros casos clínicos pediátricos con confirmación microbiológica y molecular identificados en el Hospital de Niños Roberto del Río. 


\section{Métodos}

Descripción de la institución: El estudio se desarrolló en el Hospital de Niños Roberto del Río, institución pública que da atención de salud a la población pediátrica correspondiente al Servicio de Salud Metropolitano Norte, en Santiago de Chile. El nivel de atención otorgada es de alta complejidad. Cuenta con 126 camas básicas y 50 de cuidados intensivos, 8.225 egresos y 113.824 consultas a la Unidad de Emergencia durante 2013.

Tipo de estudio y recolección de la información: Estudio descriptivo de serie de casos ocurridos entre 2012 y 2013. Una vez obtenido el consentimiento informado de cada uno de sus tutores, se revisaron sus registros clínicos para obtener los datos demográficos, presentación y evolución clínica. No se realizó análisis estadístico por no ser pertinente.

Definición de caso: Se adoptó la definición epidemiológica de caso de infección por SARM-AC establecida por Centers for Disease Control and Prevention (CDC) de E.U.A. de 2005: cualquier infección por SARM diagnosticada en un paciente ambulatorio o dentro de las $48 \mathrm{~h}$ de hospitalización, además el paciente no presenta los siguientes factores de riesgo asociados: hemodiálisis, cirugía, hospitalización durante el año anterior, presencia de un catéter permanente, de un dispositivo percutáneo en el momento del cultivo o un aislado previo de SARM ${ }^{19}$.

Estudio microbiológico e identificación de casos: A todas las cepas identificadas como $S$. aureus aisladas de líquidos estériles y secreciones se les realizó un test de sensibilidad a meticilina y otros antimicrobianos por método automatizado para determinación de la concentración inhibitoria mínima (CIM) en un equipo Vitek2 compac ${ }^{\circledR}$. Los aislados resistentes a meticilina fueron revisados si cumplían con la definición de un caso de SARM-AC. Las cepas seleccionadas fueron enviadas al ISP para estudio y confirmación molecular de los casos. En el ISP se utilizó como método de confirmación la detección del gen mec-A y gen $p v l$ a través de reacción de polimerasa en cadena (RPC). Los estudios de caracterización molecular se realizaron mediante electroforesis en gel de campo pulsado (PFGE), y la tipificación de multilocus (MLST) de acuerdo al protocolo estandarizado por MLST.net. Además se estudió el tipo de Spa, mediante la técnica genética de Spa typing con nomenclatura Ridom, que analiza la región polimórfica de la proteína A de $S$. aureus ${ }^{20}$.

\section{Resultados}

Durante los años 2012 y 2013 se identificaron 260 pacientes con aislados de $S$. aureus en líquidos estériles y secreciones, 12 de los cuales fueron resistentes a meticilina. Luego del análisis clínico y demográfico se determinó si correspondía a la definición de caso de SARM-AC.
Cuatro de los 12 casos fueron identificados como SARM$\mathrm{AC}$ y son los que a continuación se describen.

\section{Caso 1}

Escolar de 11 años de edad, género femenino, sin antecedentes de hospitalizaciones ni de patología crónica. Un mes previo a la hospitalización había recibido flucloxacilina como tratamiento de un impétigo. Su madre era portadora de un lupus eritematoso sistémico, dueña de casa y su padre, trabajador en servicios de correo internacional. La paciente sufrió una caída a nivel, por lo que consultó en la Unidad de Emergencia (UE) por dolor en la rodilla derecha. Se diagnosticó una contusión y se manejó en forma ambulatoria con inmovilización y analgesia. Dada la persistencia del dolor vuelve a consultar una semana después. Al examen físico presentaba dolor espontáneo intenso en la rodilla derecha, dolor a la palpación de la metáfisis proximal de la tibia derecha con aumento de volumen y temperatura local, sin fiebre, sin compromiso hemodinámico, ni del estado general. En los exámenes de ingreso destacaba un hemograma con leucocitosis y desviación a izquierda ( $24 \%$ baciliformes), proteína C reactiva (PCR) $270 \mathrm{mg} / \mathrm{L}$ y VHS $101 \mathrm{~mm} / \mathrm{h}$. La radiografía mostró un discreto aumento de tejidos blandos en la rodilla derecha, sin lesión ósea asociada. Se realizó un aseo quirúrgico y se inició tratamiento antimicrobiano con cloxacilina iv $(185 \mathrm{mg} / \mathrm{kg} /$ día $)$ cada $6 \mathrm{~h}$. Al tercer día post-operatorio, persistió con dolor intenso y comenzó con fiebre y compromiso del estado general. Los dos hemocultivos y el cultivo de tejido óseo fueron positivos para SARM (Tabla 1), por lo que se inició vancomicina, aislamiento de contacto según la norma institucional y se realizó un nuevo aseo quirúrgico. Dada la persistencia de la fiebre se realizó un cintigrama óseo trifásico, el cual demostró un aumento de la actividad osteoblástica localizado en la metáfisis de la tibia proximal derecha (Figura 1). La evolución fue tórpida, con persistencia de la fiebre hasta 15 días después de haber iniciado

\begin{tabular}{|c|c|c|c|c|}
\hline & $\begin{array}{c}\text { Caso } 1 \\
\text { CIM }\end{array}$ & $\begin{array}{c}\text { Caso } 2 \\
\text { CIM }\end{array}$ & $\begin{array}{c}\text { Caso } 3 \\
\text { CIM }\end{array}$ & $\begin{array}{c}\text { Caso } 4 \\
\text { CIM }\end{array}$ \\
\hline Ciprofloxacina & $\leq 0,5$ & $\leq 0,5$ & $\leq 0,5$ & $\leq 0,5$ \\
\hline Clindamicina & $\leq 0,25$ & $\leq 0,25$ & $\leq 0,25$ & $\leq 0,25$ \\
\hline Cotrimoxazol & $\leq 10$ & $\geq 320$ & $\leq 10$ & $\leq 10$ \\
\hline Eritromicina & $<0,25$ & $\leq 0,25$ & $\leq 0,25$ & $\leq 0,25$ \\
\hline Rifampicina & $\leq 0,5$ & $\leq 0,5$ & $\leq 0,5$ & $\leq 0,5$ \\
\hline Tetraciclina & $\leq 1,0$ & $\leq 1,0$ & $\leq 1,0$ & $\leq 1,0$ \\
\hline Vancomicina & $\leq 0,5$ & 1,0 & $\leq 0,5$ & $\leq 0,5$ \\
\hline Gentamicina & $\leq 0,5$ & $\leq 0,5$ & $\leq 0,5$ & $\leq 0,5$ \\
\hline
\end{tabular}


vancomicina, requiriendo múltiples aseos quirúrgicos en los que se encontraron colecciones y daño articular. Los cultivos intraoperatorios persistieron positivos hasta 12 días después de haber iniciado vancomicina. Por la persistencia de la fiebre se descartaron focos secundarios u otra infección. Se realizó un estudio inmunológico básico que resultó normal. El día 18 de tratamiento con vancomicina presentó un exantema máculo-papular morbiliforme, que fue considerada como una reacción adversa a fármacos, por lo que se cambió la terapia a clindamicina iv. Evolucionó afebril y sin dolor local, completando en total 56

Figura 1. Cintigrama óseo trifásico, caso 1.

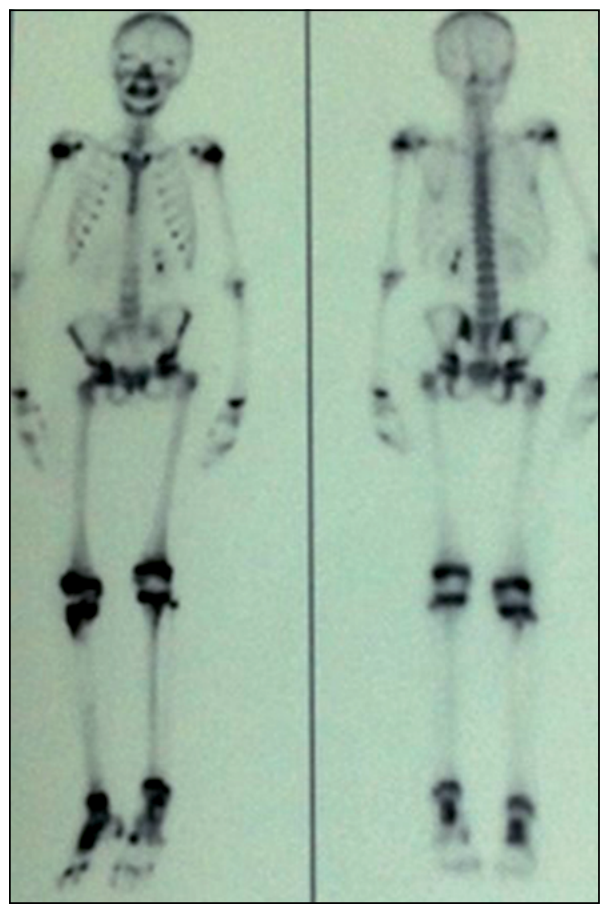

días de tratamiento antibacteriano: 17 días de vancomicina y 39 días de clindamicina. Fue dada de alta con parámetros inflamatorios en descenso (VHS $28 \mathrm{~mm} / \mathrm{h}$ y PCR 19,2 $\mathrm{mg} / \mathrm{L})$, y tratamiento con linezolid vía oral $(300 \mathrm{mg}$, dos veces al día), por 20 días. El ISP confirmó que la cepa fue SARM, PVL negativa. Además, se realizó un estudio de portación nasal familiar en que la madre resultó ser positiva por lo que se realizó una decolonización con mupirocina tópica (Tabla 2). El análisis genético y la caracterización molecular de ambas cepas demostró la ausencia del marcador PV-L y determinaron un mismo subtipo genético por PFGE (CL-SAU-COM-SMA-017) y por MLST al tipo de secuencia ST8 (Tabla 3 y Figura 4).

\section{Caso 2}

Varón de 9 años de edad, sin antecedentes de enfermedades crónicas, hospitalizaciones o uso de antimicrobianos recientes. Tenía padres sanos y una abuela con antecedentes de una hospitalización en los dos meses previos a la consulta. Su grupo familiar pertenecía a la etnia gitana, con hábitos nómades y habitación en carpas. Recientemente habían acampado en la Región de la Araucanía junto a sus primos, tíos y abuelos. Consultó en la UE por dos días de fiebre hasta $39^{\circ} \mathrm{C}$ axilar y dolor progresivo de tobillo derecho que comenzó tras una contusión, a lo que se agregó un aumento de volumen, calor local e impotencia funcional. Los síntomas se habían manejado con antiinflamatorios no esteroidales sin respuesta. Se internó con el diagnóstico de una artritis séptica de tobillo derecho. Se encontraba febril, con un hemograma con leucocitosis de $25.300 / \mathrm{mm}^{3}$ y una PCR de $171 \mathrm{mg} / \mathrm{L}$. Se realizó un aseo quirúrgico e inició cloxacilina $160 \mathrm{mg} / \mathrm{kg} /$ día iv. Evolucionó decaído, febril, con compromiso del estado general. La herida operatoria dio salida a material purulento requiriendo un nuevo aseo quirúrgico. A las

\begin{tabular}{|c|c|c|c|c|c|c|}
\hline Caso & $\begin{array}{c}\text { Género y } \\
\text { edad }\end{array}$ & Antecedentes & Cuadro clínico & Tratamiento & Comuna residencia & Estudio portación \\
\hline 1 & $\begin{array}{l}\text { Mujer } \\
10 \text { años }\end{array}$ & Uso flucloxacilina & Osteomielitis & $\begin{array}{l}\text { Vancomicina } \\
\text { Clindamicina } \\
\text { Linezolid }\end{array}$ & Conchalí & $\begin{array}{l}\text { Madre: SARM } \\
\text { Padre: SASM } \\
\text { Hermana: SASM }\end{array}$ \\
\hline 2 & $\begin{array}{l}\text { Hombre } \\
9 \text { años }\end{array}$ & Hábitos nómades & Osteomielitis & Clindamicina & La Florida & $\begin{array}{l}\text { Papá, abuela y tíos: (-) } \\
\text { Madre: SASM } \\
\text { Hermano: SASM } \\
\text { Primos: SARM }\end{array}$ \\
\hline 3 & $\begin{array}{l}\text { Hombre } \\
13 \text { años }\end{array}$ & Picaduras de insectos & Celulitis & Clindamicina & Independencia & $\begin{array}{l}\text { Madre: (-) } \\
\text { Padre: (-) } \\
3 \text { hermanos: (-) } \\
\text { Tía: (-) } \\
2 \text { primas: (-) }\end{array}$ \\
\hline 4 & $\begin{array}{l}\text { Hombre } \\
11 \text { años }\end{array}$ & Ninguno & Absceso perirrenal & $\begin{array}{l}\text { Cefotaxima } \\
\text { Vancomicina } \\
\text { Meropenem }\end{array}$ & Recoleta & $\begin{array}{l}\text { Madre: (-) } \\
\text { Padre: (-) }\end{array}$ \\
\hline
\end{tabular}




\begin{tabular}{|c|c|c|c|c|c|}
\hline & Fenotipo resistencia & Confirmación ISP & PVL & PFGE & MLST \\
\hline Caso 1 & Cloxacilina & $\begin{array}{l}\text { mecA positivo } \\
\text { femA positivo } \\
\mathrm{CIM} \text { vancomicina } 1 \mathrm{ug} / \mathrm{ml} \text {. }\end{array}$ & Negativo & CL-SAU-COM-SMA-017 & ST8 \\
\hline Caso 2 & $\begin{array}{l}\text { Cloxacilina } \\
\text { Cotrimoxazol }\end{array}$ & $\begin{array}{l}\text { mecA positivo } \\
\text { femA positivo } \\
\mathrm{CIM} \text { vancomicina } 1 \mathrm{ug} / \mathrm{ml} \text {. }\end{array}$ & Negativo & CL-SAU-COM-SMA020 & ST8 \\
\hline Caso 3 & Cloxacilina & $\begin{array}{l}\text { mecA positivo } \\
\text { femA positivo } \\
\mathrm{CIM} \text { vancomicina } 1 \mathrm{ug} / \mathrm{ml} \text {. }\end{array}$ & Negativo & CL-SAU-COM-SMA003 & ST8 \\
\hline Caso 4 & Cloxacilina & $\begin{array}{l}\text { mecA positivo } \\
\text { femA positivo } \\
\text { CIM vancomicina } 1 \mathrm{ug} / \mathrm{ml} \text {. }\end{array}$ & Positivo & CL-SAU-COM-SMA-002 & $\begin{array}{c}\text { ST731 } \\
\text { (complejo clonal ST30) }\end{array}$ \\
\hline
\end{tabular}

$48 \mathrm{~h}$ se informaron dos hemocultivos, líquido articular y tejido óseo positivo para SARM (Tabla 1). Se cambió la terapia antibacteriana a clindamicina $30 \mathrm{mg} / \mathrm{kg} /$ día iv y se implementaron medidas de aislamiento de contacto según la norma institucional. Se descartaron focos a distancia mediante un cintigrama óseo (Figura 2), radiografía de tórax y ecocardiografía. Requirió varios aseos quirúrgicos durante su hospitalización, evolucionando lentamente con disminución de los parámetros inflamatorios y recuperación funcional hasta completar seis semanas de tratamiento antimicrobiano efectivo. La cepa aislada fue confirmada como SARM con ausencia del marcador PVL. La caracterización molecular correspondió al subtipo genético CL-SAU-COM-SMA020 (PFGE) y secuencia ST8 por MLST (Tabla 3 y Figura 4). Se realizó estudio de portación nasal a la familia (Tabla 2). A todos los portadores de $S$. aureus se les indicó mupirocina tópica para su erradicación.

\section{Caso 3}

Varón de 13 años de edad, sin antecedentes de hospitalizaciones, uso previo de antimicrobianos, ni contacto con personas recientemente internadas. Consultó en la UE por aumento de volumen y eritema en codo y antebrazo izquierdo, dolor local y leve impotencia funcional de una semana de evolución, secundario a múltiples picaduras de insecto. Al examen físico se encontraba afebril, sin compromiso del estado general y hemodinámicamente estable. Presentaba un aumento de volumen eritematoso de 6 x $5 \mathrm{~cm}$, en relación a dos lesiones costrosas en el codo izquierdo. Se realizó aseo de la lesión con descostraje y salida de secreción purulenta, de la que se tomó cultivo. Dentro de los exámenes tenía una PCR $8 \mathrm{mg} / \mathrm{L}$ y un hemograma normal. Se realizó una ecografía que mostró un edema subcutáneo sin compromiso profundo. Se internó para tratamiento antimicrobiano con cloxacilina iv 100

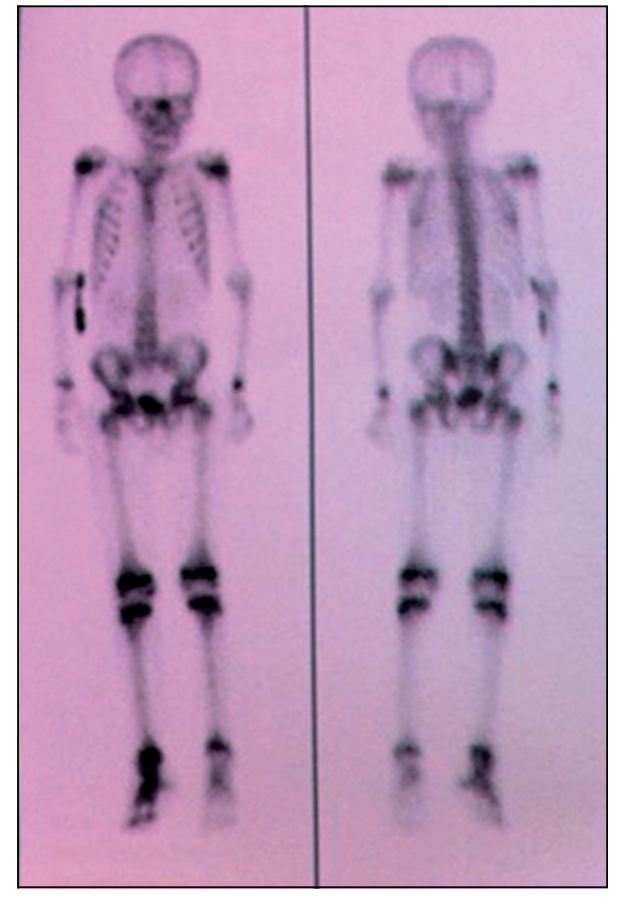

Figura 2. Cintigrama óseo trifásico, caso 2.

$\mathrm{mg} / \mathrm{kg} /$ día, cada $6 \mathrm{~h}$. Durante los primeros días de hospitalización, evolucionó con dolor, eritema y persistencia de aumento de volumen, siempre afebril y sin impotencia funcional. El cultivo fue positivo a SARM (Tabla 1) por lo que se cambió a clindamicina iv $30 \mathrm{mg} / \mathrm{kg} /$ día, cada $8 \mathrm{~h}$. Evolucionó favorablemente, con disminución gradual del dolor, del tamaño de la lesión y del eritema. Tras completar siete días de clindamicina y con regresión de las lesiones se dio de alta para completar tratamiento antimicrobiano vía oral en su hogar. La cepa aislada fue estudiada en el ISP confirmando SARM y ausencia del marcador de PV- 
L. La caracterización molecular correspondió al subtipo genético CL-SAU-COM-SMA003 (PFGE) y secuencia ST8 por MLST (Tabla 3 y Figura 4). Se realizó cultivo de portación nasal intrafamiliar para detección de $S$. aureus, resultando todos negativos (Tabla 2).

\section{Caso 4}

Escolar de 11 años de edad, género masculino, sin antecedentes personales ni familiares de patologías crónicas, hospitalizaciones, ni uso de antibacterianos recientes. Consultó por astenia, adinamia y lumbalgia de tres semanas de evolución posterior a un trauma dorsolumbar izquierdo, asociado a tres días de fiebre hasta $39^{\circ}$ C. Se internó para estudio evolucionando con fiebre y PCR hasta $150 \mathrm{mg} / \mathrm{L}$. A las 48 h, se realizó una ecografía abdominal que mostró una colección renal izquierda, por lo que inició cefotaxima en forma empírica. Al día siguiente se cambió a cloxacilina $(170 \mathrm{mg} / \mathrm{kg} /$ día $)$ cada $6 \mathrm{~h}$. Se realizó una angio-TAC que evidenció un absceso renal izquierdo de $5 \mathrm{~cm}$ de diámetro (Figura 3). Al cuarto día de tratamiento, dada persistencia de la fiebre e incremento de PCR hasta $270 \mathrm{mg} / \mathrm{L}$, se cambió esquema a vancomicina (40 mg/ $\mathrm{kg} /$ día) y meropenem $(60 \mathrm{mg} / \mathrm{kg} /$ día). Luego de seis días de vancomicina y con una evolución clínica desfavorable, aumento de los parámetros inflamatorios y del tamaño de la lesión renal se trasladó a otra institución para la instalación de un catéter ureteral (pig-tail) y drenaje de la colección renal, a la que se tomó una muestra para cultivo. $\mathrm{Al} 5^{\circ}$ día post-operatorio bajó

Figura 3. Imagen de TAC abdominal con contraste BCF.

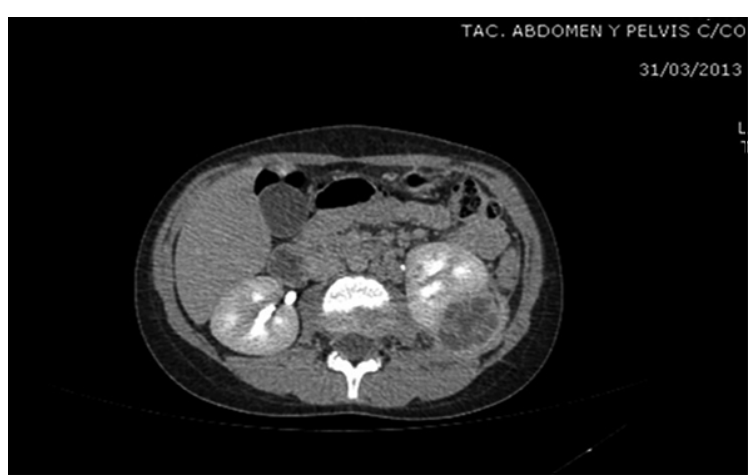

la fiebre, con descenso de parámetros inflamatorios. El resultado del cultivo fue positivo para SARM (Tabla 1). Con el informe microbiológico se suspendió meropenem y se mantuvo vancomicina con buena respuesta clínica y definitivamente afebril después de 12 días del drenaje quirúrgico, normalización de PCR, función renal siempre conservada e imagen ecográfica con absceso en regresión. Completó un total de 36 días de tratamiento con vancomicina. Se confirmó la cepa como SARM, PV-L positivo. La caracterización molecular correspondió al subtipo CL-SAU-COM-SMA-002 (PFGE) y al ST731 perteneciente al CC 30 por MLST (Tabla 3 y Figura 4). Se realizó estudio de portación nasal a ambos padres, hermanos y abuelos, todos negativos (Tabla 2).

\section{Discusión}

Esta serie de casos es, en nuestro conocimiento, la primera publicación de infecciones pediátricas por SARM$\mathrm{AC}$ en Chile. El año 2006 se publicaron los primeros casos chilenos en pacientes adultos ${ }^{17}$. Desde entonces, en nuestro país las infecciones por SARM-AC siguen siendo de baja incidencia. El último reporte nacional de vigilancia del ISP mostró 122 aislados confirmados como SARM-AC ${ }^{15}$. Así mismo, la vigilancia dentro de nuestro hospital reveló que durante los años 2012 y 2013, de los 260 aislados de $S$. aureus en líquidos estériles y secreciones, sólo 12 eran resistentes a meticilina (4,6\%), y de éstos cuatro resultaron ser provenientes de la comunidad, casos anteriormente expuestos. Sin embargo, estudios en otros países latinoamericanos, muestran tasas mayores de prevalencia de SARM-AC, con un gran número de casos pediátricos, lo que dan cuenta de un grave problema de salud pública en esos países ${ }^{21,22}$. En estos estudios las principales formas de presentación clínica son las infecciones de piel y tejidos blandos, que en nuestra serie se encontró sólo en uno de los cuatro casos. Así mismo, tanto en Sudamérica como en E.U.A. se han reportado tasas de incidencia altas y en ascenso de infecciones invasoras por este microorganismo desde el $2002^{21-27}$.

La baja incidencia de infecciones por SARM-AC en Chile es el fundamento que sostiene que frente a una infección de probable etiología estafilocócica adquirida

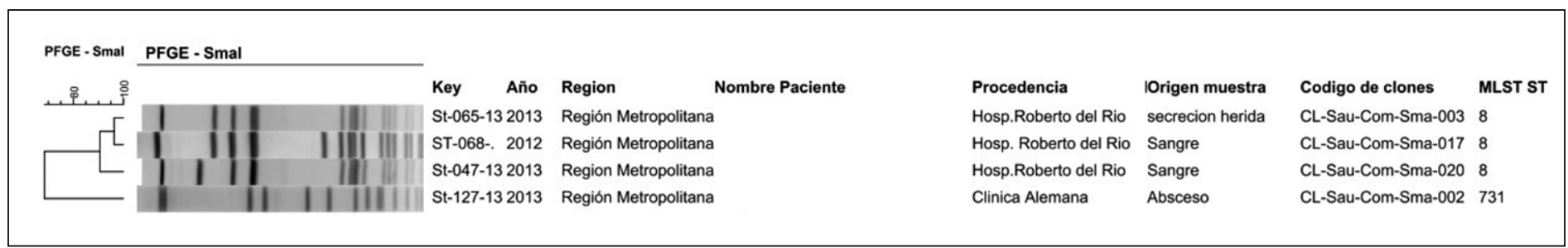

Figura 4. Electroforesis de campo pulsado (PFGE) de las cuatro cepas aisladas. 
en la comunidad, cloxacilina siga siendo el antimicrobiano de elección en nuestro país. De todos modos debemos tener un alto nivel de sospecha de infección por SARM-AC frente a escolares con cuadros clínicos como infecciones de piel y tejidos blandos, abscesos profundos, ostomielitis o artritis que no evolucionan favorablemente a las $48 \mathrm{~h}$ después de iniciado un tratamiento adecuado con cloxacilina o de un aseo quirúrgico cuando existen colecciones. En todos los casos de nuestra serie clínica, la evolución a las $48 \mathrm{~h}$ fue desfavorable, contrario a lo observado habitualmente frente a infecciones por $S$. $a u$ reus sensible a meticilina. Además, en aquellos pacientes en que se demoró el inicio de una terapia antibacteriana adecuada para este microorganismo, la evolución clínica y microbiológica fue mucho más tórpida (Tabla 4). Las cepas aisladas en estos pacientes fueron sensibles prácticamente a todos los antimicrobianos estudiados (excepto meticilina), salvo el caso 2, en el cual además se encontró resistencia a cotrimoxazol. Así entonces, frente a la sospecha de una infección por SARM-AC sugerimos un cambio de terapia antibacteriana a vancomicina o clindamicina, con un eventual ajuste posterior según el estudio de sensibilidad y la confirmación microbiológica.

Sin embargo, nuestra serie de casos es muy pequeña para poder sacar conclusiones sobre el uso empírico de antibacterianos; para ello se requiere realizar un estudio epidemiológico en niños en nuestro país.

Los hallazgos de caracterización molecular de nuestra serie confirman la existencia de casos pediátricos en nuestro país que cumplen con la definición clínicoepidemiológica de SARM-AC, pero que en la mayoría carecen del marcador PV-L. Esta situación, especialmente en pediatría, refleja la debilidad de este marcador como screening para el diagnóstico de SARM-AC e indica la importancia de la investigación epidemiológica y molecular de estos casos.

En Chile, la gran mayoría de los casos reportados corresponden a adultos de sexo masculino; $69 \%$ presentan la secuencia ST8 y todos el gen $p v l$, según el informe de ISP del $2013^{15}$. En los casos de nuestra serie, la caracterización de las cepas por MLST, mostró que tres de los cuatro subtipos corresponden a ST8, predominante en
Chile, pero en esta oportunidad, el estudio molecular reveló la ausencia del gen marcador $p v l$ en todos ellos. Sólo una cepa fue positiva para la presencia del gen $p v l$ $y$ correspondió al ST731 no reportado previamente en nuestro país. El ST731 pertenece al complejo clonal 30 (CC30) descrito en el Pacífico suroeste ${ }^{20}$.

Con respecto a la epidemiología de los complejos clonales se puede decir que ST8 del CC8 corresponde al clon pandémico de SARM ampliamente distribuido, que incluye cepas de la comunidad y hospitalarias. Se caracteriza por tener genes de virulencia que incluyen al gen $p v l$ en elementos genéticos móviles como fagos o plásmidos, lo que puede llevar a la pérdida de este gen en algunas cepas. El ST731 pertenece al CC30 que incluye cepas hospitalarias y comunitarias, una cepa importante de este complejo es PV-L positiva del ST30-MRSA-IV, clon del Pacífico suroeste que es infrecuente y que fue observada por primera vez en inmigrantes samoanos en Nueva Zelandia ${ }^{20}$.

En nuestra serie de casos encontramos además una portación familiar frecuente, lo que ya estaba descrito ${ }^{20}$. Esto nos hace inferir que hay una circulación de este microorganismo en la comunidad, tanto PV-L negativa como positiva. Todo lo anterior justifica el estudio molecular en las infecciones por este patógeno, y así generar información epidemiológica local. La pesquisa de posibles casos es de especial importancia y debe darse en el ejercicio de la pediatría ambulatoria o de urgencia teniendo un alto índice de sospecha y adquiriendo la conducta rutinaria de cultivar secreciones y/o tomar hemocultivos cuando estamos frente a un paciente con una probable infección por S. aureus. De este modo podremos vigilar la incidencia de este patógeno tanto a nivel local como nacional, en forma periódica, que nos permita una alerta precoz cuando se detecte un aumento significativo de casos, que eventualmente pudieran hacer cambiar nuestro enfrentamiento inicial y la terapia antimicrobiana empírica.

Agradecimientos: Nuestros sinceros agradecimientos a Agustín Zamorano, Judith Aguirre y Abigail Veas, tecnólogos médicos de microbiología de nuestro hospital y al equipo de traumatología.

\begin{tabular}{|c|c|c|c|c|c|}
\hline Caso & Presentación clínica & $\begin{array}{c}\text { Día de inicio de tratamiento } \\
\text { adecuado* }\end{array}$ & Duración de fiebre $^{\dagger}$ & $\begin{array}{l}\text { Duración de cultivos } \\
\text { positivos }^{\dagger}\end{array}$ & $\begin{array}{c}\text { Días de duración de proteína C } \\
\text { reactiva }>80 \mathrm{mg} / \mathrm{L}^{+}\end{array}$ \\
\hline 1 & Osteomielitis & 5 & $20 / 15$ & $17 / 12$ & $20 / 15$ \\
\hline 2 & Osteomielitis & 2 & $5 / 3$ & $2 / 0$ & $5 / 3$ \\
\hline 3 & Celulitis & 3 & NA & NA & NA \\
\hline 4 & Absceso perirrenal & 4 & $15 / 11$ & NA & $15 / 11$ \\
\hline
\end{tabular}




\section{Resumen}

Staphylococcus aureus es un patógeno conocido como causa de infecciones de piel, tejidos blandos, osteoarticulares y celulitis en niños. Estas infecciones son principalmente causadas por cepas sensibles a meticilina. Staphylococcus aureus resistente a meticilina asociado a la comunidad fue publicado por primera vez en población australiana nativa en 1993 y desde entonces se ha transformado en un patógeno cosmopolita. En Latinoamérica se publicó el primer caso en 2003 y en Chile se comunicaron los primeros casos en 2008, casi todos adultos y con antecedentes de viaje al extranjero. Nuestra serie describe cuatro casos clínicos en niños escolares, pesquisados desde el 2012 con seguimiento clínico y estudio molecular. Dos casos se presentaron como una osteomielitis de extremidad inferior y uno como una celulitis de brazo. Los tres primeros casos correspondieron a cepas leucocidina Panton Valentine (PV-L) negativa, del complejo clonal 8. El último caso fue un absceso renal, cepa PV-L positiva, perteneciente al complejo clonal 30. Esta serie es el primer reporte de casos pediátricos en Chile.

\section{Referencias bibliográficas}

1.- Lowy F D. Staphylococcus aureus infections. N Engl J Med 1998; 339: 520-32.

2.- Demerec M. Production of Staphylococcus strains resistant to various concentrations of penicillin. Proc Natl Acad Sci 1945; 31: 16-24.

3.- Barber M. Staphylococcal infections due to penicillin-resistant strains. Br Med J 1947; 2: 863-5.

4.- Cluzel R, Verner M, Vaurus R, Cluzel-Nigay M. Celbemom-resistant staphylococci. Br Med J 1961; 1: 113-4.

5.- Jevons M P. Celbenin-resistant staphylococci. Br Med J 1961; 1: 124-5.

6.- Barber M. Methicillin-resistant staphylococci. J Clin Pathol 1961; 14: 385-93.

7.- Klein E, Smith D L, Laxminarayan R. Hospitalizations and deaths caused by methicillin-resistant Staphylococcus aureus, United States, 1999-2005. Emerg Infect Dis 2007; 13: 1840-6.

8.- Udo E E. Community-acquired methicillinresistant Staphylococcus aureus: the new face of and old foe? Med Princ Pract 2013; 22 Suppl 1: 20-9.

9.- Udo E E, Pearman J W, Grubb W B. Genetic analysis of community isolates of methicillinresistant Staphylococcus aureus in Western Australia. J Hosp Infect 1993; 25: 97-108.

10.- Gosbell I B, Mercer J L, Neville S A, Crone S A, Chant K G, Jalaludin B B, et al. Non-multiresistant and multiresistant methicillin-resistant Staphylococcus aureus in community-acquired infections. Med J Aust 2001; 174: 627-30.

11.- Liassine N, Auckenthaler R, Descombes M C, Bes M, Vandenesch F, Etienne J. Communityacquired methicillin-resistant Staphylococcus aureus isolated in Switzerland contains the Panton-Valentine leukocidin or exfoliative toxin genes. J Clin Microbiol 2004; 42: 825-8.

12.- Lina G, Piemont Y, Godail-Gamot F, Bes M, Peter M O, Gauduchon V, et al. Involvement of Panton-Valentine leukocidin-producing Staphylococcus aureus in primary skin infections and pneumonia. Clin Infect Dis 1999; 29: 1128-32.

13.- Diep B A, Sensabaugh G F, Somboona N, Carleton H A, Perdreau-Remington F. Widespread skin and soft-tissue infections due to two methicillin-resistant Staphylococcus aureus strains harbouring the genes for Panton-Valentine leucocidin. J Clin Microbiol 2004; 42: 2080-4.

14.- Rodríguez-Noriega E, Seas C. Patrón cambiante de los clones de Staphylococcus aureus resistente a meticilina en América Latina: Implicancias para la práctica clínica en la región. Rev Chilena Infect 2010; 27 (Supl 2): S59-69.

15.- Vigilancia de Staphylococcus aureus meticilina resistente adquirido en la comunidad. Boletín ISP abril de 2013; 3 (7). (Fecha de acceso: 10 de diciembre de 2014) http://www.ispch. $\mathrm{cl} /$ sites/default/files/S\%20\%20aureus\%20 comunitario19-07-2013\%20final.pdf

16.- Galiana A. Infección por Staphylococcus aureus meticilino resistente adquirido en la comunidad. Arch Pediatr Urug 2003; 74: 26-9.

17.- Noriega L M, González P, Hormazábal J C, Pinto C, Canals M, Munita J M, et al. Staphylococcus aureus comunitario resistente a cloxacilina: Comunicación de los primeros cinco casos descritos en Chile. Rev Med Chile 2008; 136: 885-91.

18.- Ordinario MINSAL B51 No 3134,26 de junio de 2007. Alerta frente a casos de Staphylococcus aureus meticilino resistente de origen comunitario. Fecha de acceso: 10 de diciembre de 2014. http://epi.minsal. $\mathrm{cl} /$ epi/html/normas/circul/ORD3134_ AlertaFrenteSTAPHYKICICCUS.pdf

19.- Morrison M A, Hageman J C, Klevens R M. Case definition for community-associated methicillin-resistant Staphylococcus aureus. J Hosp Infect 2006; 62: 241.

20.- Monecke S, Coombs G, Shore A C,
Coleman D C, Akpaka P, Borg M, et al. A field guide to pandemic, epidemic and sporadic clones of methicillin-resistant Staphylococcus aureus. PloS One 2011; 6: e17936.

21.- Paganini H, Della Latta M, Muller Opet B, Ezcurra G, Uranga M, Aguirre C, et al. Estudio multicéntrico sobre las infecciones pediátricas por Staphylococcus aureus meticilino-resistente provenientes de la comunidad en la Argentina. Arch Argent Pediatr 2008; 106: 397-403.

22.- Paganini H, Della Latta M, Soto A, Casimir L, Mónaco A, Verdaguer V, et al. Bacteriemias por Staphylococcus aureus adquiridas en la comunidad: 17 años de experiencia en niños de la Argentina. Arch Argent Pediatr 2010; 108: 311-7.

23.- Gerber J S, Coffin S E, Samrters S A, Zaoutis T E. Trends in the incidence of methicillin-resistant Staphylococcus aureus infection in children's hospitals in the United States. Clin Infect Dis 2009; 49: 65 -71.

24.- Iwamoto M, Mu Y, Lynfield R, Bulens S N, Nadle J, Aragon D, et al. Trends in invasive methicillin-resistant Staphylococcus aureus infections. Pediatrics 2013; 132: e817-24.

25.- Paganini H, Della M P, Muller B, Ezcurra G, Uranga $\mathrm{M}$, Aguirre $\mathrm{C}$, et al. Infecciones por Staphylococcus aureus resistente a meticilina adquirida en la comunidad en niños antes sanos y en niños relacionados al hospital en la Argentina. Rev Chilena Infectol 2009; 26 : 406-12.

26.- Fridkin S, Hageman J C, Morrison M, Sanza L T, Como-Sabetti K, Jernigan J A, et al. Methicilin-resistant Staphylococcus aureus disease in three communities. N Eng J Med 2005; 352: 1436-44.

27.- Hsiang M S, Shiau R, Nadle J, Chan L, Lee B, Chambers H, et al. Epidemiologic similarities in pediatric community associated methicillin-resistant and methicillin-sensitive Staphylococcus aureus in the San Francisco bay area. J Ped Infect Dis Soc 2012; 1: 200-11. 